\title{
Interação universidade- empresa na sociedade do conhecimento: reflexões e realidade
}

\section{Teresa Lenice Nogueira da Gama Mota}

\section{Resumo}

O presente trabalho pretende conduzir a uma reflexão sobre universidade-empresa, elemento vital na sociedade do conhecimento.

Na introdução, são apresentadas as razões da importância desse processo de interação diante do novo paradigma tecnológico; conduz-se aos principais problemas da ciência e da tecnologia na América Latina com particular ênfase para a economia brasileira, tendo como pano de fundo a montagem de um sistema de inovação. $\mathrm{Na}$ seção 2, são analisados os principais mecanismos de interação existentes, suas vantagens e desvantagens. Finalmente, na seção 3, discorre-se sobre o papel dos agentes de interação nesse trabalho de interface, descrevendo-se o perfil adequado dos agentes e os conhecimentos que devem possuir, seja do ambiente universitário, seja do setor empresarial, sem perder de vista, é claro, os diversos modelos de desenvolvimento tecnológico. Nessa mesma seção, finaliza-se o trabalho com uma reflexão sobre o papel do Estado brasileiro como indutor do desenvolvimento tecnológico, inclusive no apoio às instituições de interface.

\section{Palavras-chave}

Sociedade do conhecimento; Inovação tecnológica; Interação universidadeempresa.

\section{INTRODUÇÃO}

"Neste final de século, o processo de mudança tecnológica atingiu uma velocidade e importância nunca antes vistas na história humana"*. As aceleradas, profundas e abrangentes transformações marcam o esgotamento da sociedade industrial, e o ingresso na sociedade do conhecimento coloca-se como fator chave para o desenvolvimento econômico de regiões e países.

Desse modo, a valorização das atividades de ciência e tecnologia e de pesquisa e desenvolvimento, para estados nacionais e empresas, são evidências claras desse processo.

Nesse contexto, a inovação tecnológica surge como a variável decisiva para alcançar e sustentar vantagens competitivas de empresas, setores e espaços econômicos.

Como destaca Porter* ${ }^{\star *}$ à medida que se alcança maior grau de interdependência econômica, política e tecnológica, entre os distintos agentes econômicos e países do mundo, a inovação tecnológica passa a ser um elemento chave da competitividade nacional e internacional, a ponto de se afirmar que a competitividade de uma nação depende da capacidade de inovar de suas indústrias.
Sabe-se, contudo, que a dinâmica da inovação depende mais dos processos de aprendizagem do conhecimento do que da disponibilidade de recursos, assim como seu impulso ocorre de maneira sistêmica. Desta forma, ela está fortemente vinculada aos processos de interação entre as organizações e agentes que permitem gerar, reproduzir e retroalimentar processos de aprendizagem e convertê-los em atividade inovadora. Ainda que a empresa seja considerada a unidade básica para materializar a acumulação tecnológica, seu desempenho está fortemente condicionado à densidade da infra-estrutura tecnológica existente no seu entorno, que pode assegurar externalidades dinâmicas positivas* . Observa-se essa circunstância na forte integração das atividades dos sistemas de ciência e tecnologia dos países de economia industrial avançada.

Assim, convém que se tenha como pano de fundo alguns dos principais problemas da ciência e da tecnologia na América Latina.

Segundo Font ${ }^{* *}$, os principais problemas enfrentados na América Latina são os seguintes: a) falta de comunicação interinstitucional e ausência de sistemas nacionais de inovação - inexistência de uma linguagem comum entre empresários e pesquisadores; débeis mecanismos de coordenação entre os próprios organismos que executam atividades científicas e tecnológicas; escasso nível

\footnotetext{
* DUTRENIT. "Sistema Nacional de Innovación" (mimeo).

** FONT. Innovación tecnológica y competitividad, p. 99.
} 
de complementariedade entre o setor empresarial e o setor científico-tecnológico. Na verdade, parece existir um sistema científico e tecnológico, e não um sistema de inovações, na medida em que se proporcionou mais oferta de conhecimentos do que se gerou inovações. Um sistema nacional de inovação se diferencia do conceito tradicional do sistema de ciência e técnica pela maior abertura e flexibilidade nos nexos entre instituições, aí compreendidas aquelas dedicadas à pesquisa e desenvolvimento, bem como os potenciais usuários, as entidades governamentais e privadas vinculadas à geração, difusão, adaptação e utilização das tecnologias nacionais e importadas; b) ausência de políticas e falta de constância na aplicação das existentes - aspecto focal da ação governamental dos países desenvolvidos; c) crise no sistema educacional - insuficiente formação universitária, principalmente em setores de fronteira; d) frágil mecanismo de formação de uma cultura industrial relacionado à compra de "pacotes tecnológicos", sem um processo posterior de assimilação e adaptação das tecnologias, principalmente no caso de tecnologias importadas operadas por monopólios ou empresas multinacionais; e) carência de instrumentos básicos para desenvolver competitividade tecnoeconômica - insuficiente desenvolvimento e aplicação de enfoques integrados de planejamento estratégico, prospecção, gestão tecnológica, monitoração da inteligência, entre outros; f) limitada projeção da cooperação internacional - frágeis vínculos de cooperação internacional em matéria de ciência e tecnologia entre os países da região. As características essenciais do novo padrão de desenvolvimento científico-tecnológico baseiam-se em um amplo e complexo sistema de inter-relações de pesquisas, produtivas e comerciais em escala internacional. O "tecnoglobalismo" ou internalização da tecnologia constitui um requisito essencial do desenvolvimento contemporâneo da parte da produção que se apóia diretamente na ciência e tecnologia.
Tais problemas acentuam-se com a emergência do novo paradigma produtivo em torno da difusão das tecnologias da informação e com a globalização dos mercados, pois, como já dissemos, passa a haver valorização do papel desempenhado pelos sistemas de C\&T como fator chave da construção de vantagens competitivas.

Este fato tem levado à crescente ação dos governos nacionais para estimular o desenvolvimento tecnológico. No caso da economia brasileira, se antes a lógica autárquica possibilitou a expansão da matriz industrial integrada, com tecnologias difundidas e banalizadas com elevado "gap" técnico ao padrão encontrado no mercado mundial, agora a inserção competitiva impõe uma especialização produtiva nas áreas em que o país exibe vantagens comparativas. Para participar do mercado global no novo jogo, o acesso à tecnologia é muito mais restrito, por sua importância estratégica para as empresas que objetivam atingir tal mercado.

Para manterem-se nos mercados, as empresas precisam liderar ou acompanhar a fronteira tecnológica, e, como estas atividades não se restringem às ações desenvolvidas internamente nas empresas, mas dependem fortemente das externalidades decorrentes da infra-estrutura tecnológica, os instrumentos de interação tornam-se elementos vitais na formação de competências para as firmas.

Acreditar que as empresas brasileiras levam vantagens por não precisarem desenvolver tecnologia para assegurar o seu processo de acumulação é ilusório. Como assinala o professor Adriano Dias "incentivar o desenvolvimento tecnológico faz, então, parte das medidas defensivas que o governo de um país periférico pode adotar para compensar parcialmente as desvantagens dos capitais de seus agentes nacionais"*.

* DIAS. Alta tecnologia, p. 120-121.
Assim, a estratégia de inovação no Brasil deve estar orientada para maior articulação com o setor produtivo, bem como para as atividades imitativasadaptativas, deixando a geração de tecnologias inteiramente novas, principalmente as relativas aos novos produtos, para os países centrais, exceção ao desenvolvimento de produtos que não se constituem interesses daqueles, mas o são para os países periféricos.

Outro aspecto que o sistema de inovação no Brasil deve estar atento refere-se ao desenvolvimento de pesquisa de produtos importados, que hoje galgam espaço no mercado interno, em situação de baixo risco do ponto de vista da aceitação da inovação. Nessas circunstâncias, há vantagens de adaptação e desenvolvimento. Desse modo, é necessário caminhar dentro de fronteiras tecnológicas tendo como estratégias a imitação, a adaptação e a otimização, utilizandose da engenharia reversa.

Há de se ressaltar, porém, que a competitividade necessária para participação no mercado internacional requer a participação das economias periféricas em desenvolvimentos tecnológicos ligados à microeletrônica, à biotecnologia e aos novos materiais. O sistema de C\&T dos países como o Brasil deve ficar atento à necessidade de desenvolver capacitação tecnológica nessas áreas, para absorver o processo de transferência de tecnologia.

Luciano Coutinho argumenta que “...não se trata apenas de reverter a tendência de retração das atividades tecnológicas no Brasil. O esforço necessário à superação da atual fragilidade tecnológica nacional requer também a indução de uma mudança fundamental nas estratégias industriais. No cerne de tal mudança, estão obviamente os objetivos de buscar o aprendizado e a capacitação cumulativos e persistentes em engenharia de processos e produtos e a prática de P\&D. Acima de tudo, ressalta-se que a internalização de atividades e objetivos tecnológicos precisa tornar-se uma dimensão significativa e permanente das estratégias do setor empresarial"*.

* COUTINHO. Superação da fragilidade tecnológica e a ausência de cooperação, p. 119. 
Lembra, ainda, que "As principais conclusões do Estudo da Competitividade da Indústria Brasileira ressaltam que um potencial de extrema importância deixou de ser plenamente utilizado pela indústria brasileira como fator de aumento de sua competitividade: as oportunidades apresentadas por investimentos no desenvolvimento de capacidade inovativa e em processos criativos de aprendizado conjunto"*.

Entre as macrodiretrizes apontadas por aquele estudo para a superação da fragilidade tecnológica e a ausência de cooperação no sistema de inovação brasileiro, pelo menos quatro podem ser vistas como instrumentos de interação. Senão vejamos:

1) estimular o setor privado (produtivo e financeiro) a reforçar suas atividades relacionadas à educação, ciência e tecnologia, incentivando as instituições privadas a incluir tais atividades dentro de uma dimensão significativa e permanente de suas estratégias, estimulando e atraindo investimentos privados para estas atividades.

2) Aumentar a conectividade entre os diversos agentes do sistema de C\&T e induzir a cooperação como forma de expandir e acelerar o processo de aprendizado conjunto. Tal cooperação deverá envolver os diversos tipos de empresas - buscando-se principalmente explorar as interfaces existentes nas cadeias de fornecedores (de insumos, bens de capital e demais intermediários), prestadores de serviços, produtores e usuários. Deverá ser igualmente estimulada a cooperação entre empresas e entidades de pesquisa, prestadores de serviços tecnológicos, instituições governamentais e qualquer outra entidade ou conjunto de entidades que possam contribuir positivamente no esforço de dinamização tecnológica do setor industrial.

3) Promover rearticulação em novas bases da infra-estrutura tecnológica estatal e privada de forma diretamente coordenada com a iniciativa empresarial.

\footnotetext{
* COUTINHO. Superação da fragilidade tecnológica e a ausência de cooperação, p. 119.
}

4) Implantar um sistema para a identificação de oportunidades científicas e tecnológicas e apoiar a montagem e o reforço de programas que garantam a rápida disseminação de informações científicas e tecnológicas, a efetiva difusão dos conhecimentos e tecnologias de interesse do setor produtivo e também a disseminação das possibilidades reais de resposta da competência técnico-científica instalada no país aos problemas de produção".

Assim, o momento é mais do que favorável a um repensar de todos os instrumentos de interação universidadeempresa.

\section{MECANISMOS DE INTERAÇÃO UNIVERSIDADE-EMPRESA}

Conforme assinalamos anteriormente, todo o nosso enfoque estará voltado para a sociedade do conhecimento e, como tal, objetivando a inovação.

Sabe-se que a eficiência de um sistema de inovação depende da interação entre vários subsistemas. Nesse contexto nos prenderemos aos subsistemas científico-tecnológico e ao subsistema produtivo. De início, é importante assinalar que cabe ao Estado criar condições para que esta interação ocorra de forma a colaborar para o objetivo maior de capacitar tecnologicamente o sistema produtivo.

Iniciemos afirmando que interações de caráter individual requerem menos esforço para estabelecer-se e manterse do que interações de caráter institucional. Isso nos levará a refletir que mecanismos devem ser acionados e que conhecimentos sobre as instituições deveremos possuir para melhor promover interações formais.

Conforme assinala Ripper Filho, "Cabe observar que interações entre indivíduos requerem bem menos esforço do que interações formais entre instituições. Isto significa que formas de interação que envolvem participação individual são, em geral, mais eficientes e estáveis, explicando, por exemplo, por que nos países desenvolvidos a principal forma de interação entre universidade e empresa é a consultoria individual de docentes"*.

\footnotetext{
${ }^{8}$ RIPPER FILHO. Ciência e tecnologia: para que? como?, p. 141.
}

É aquele mesmo autor quem também assinala: "Embora com objetivos bastante diferenciados, universidades, institutos e empresas são parte de um sistema e devem interagir de forma a maximizar os benefícios para seus objetivos e, conseqüentemente, para a sociedade como um todo. Entretanto, temos que tomar consciência de que a interação entre duas instituições requer um esforço de cada parte, tanto para ser iniciada, como para ser mantida; assim sendo, ela só é estável se as vantagens percebidas superarem, significativamente, este esforço. Estas vantagens têm que estar ligadas aos seus objetivos básicos, ou seja, deve haver, numa universidade, uma percepção de que a interação contribui para a sua missão de formar recursos humanos; (...) e a empresa tem que ver nela uma contribuição direta ou indireta para sua lucratividade.

Por outro lado, instituições têm vocações mais rígidas do que indivíduos; fora dessas vocações elas são pouco eficientes. Se, para atingir certos objetivos, procuramos forçá-las a agir fora destas vocações, as ineficiências são, em geral, muito maiores do que os possíveis benefícios. Assim, temos de objetivar a interação entre instituições, e não a integração delas. As vocações das instituições são, primariamente, determinadas pelos seus objetivos reais, nem sempre somente aqueles explicitados publicamente. Fatores culturais, desenvolvidos ao longo do processo histórico, também determinam esta vocação. Assim sendo, ao planejarmos incentivos à interação entre instituições, devemos entender a natureza de suas vocações e, em segundo lugar, quais benefícios de fato podem ser auferidos por meio da interação.

O principal benefício para a universidade, da interação com outras instituições, é o conhecimento que ela adquire sobre o funcionamento e a necessidade das instituições para as quais ela deve estar formando recursos humanos, ao contrário da visão hoje corrente, mesmo nos países desenvolvidos, onde não é muito comum as empresas contratarem pesquisas na universidade." 
E completa: "A universidade também constitui um reservatório de conhecimentos muito mais variado e amplo do que é possível reunirem outras instituições"*.

Citando novamente Ripper Filho, "Em todo o mundo, o mecanismo mais eficiente de interação institucional é a participação temporária e, em tempo limitado, de profissionais de uma instituição nas atividades de outras. A forma mais comum é a consultoria prestada por professores universitários ou por pesquisadores de institutos, em atividades nas empresas ou em institutos de pesquisa. Os conhecimentos trazidos, pelo profissional, sobre a cultura e sobre as necessidades das empresas, para a sua instituição, amplamente compensam 'o tempo perdido'. Afinal, sem este conhecimento, as universidades e institutos não poderão, com eficiência, planejar suas próprias atividades de formação de recursos humanos e de pesquisa. A participação de profissionais da empresa em atividades da universidade, embora menos comum, é também bastante útil nesse processo de aproximação. A consultoria não deve ser encarada como a solução de problemas salariais. Entretanto, não se pode negar que, nos países desenvolvidos, os rendimentos da consultoria permitem às universidades reter, em tempo integral, pessoal altamente qualificado nos campos onde a demanda do mercado de trabalho é intensa. Como ainda há barreiras culturais à utilização ampla da consultoria, o governo deveria criar, temporariamente, mecanismos para encorajar seu uso, como, por exemplo, linhas de crédito.

Criação de empresas por pesquisadores universitários é um dos mais eficientes mecanismos de transferência de conhecimentos e de geração de interações estáveis. Um pesquisador universitário que se tornou empresário é uma pessoa com conhecimento das duas culturas; ele, naturalmente, percebe a importância da interação e saberá como enfrentar as dificuldades para efetivá-las. Este mecanismo é hoje fortemente inibido pelo desconhecimento que um pesquisador tem das

\footnotetext{
* RIPPER FILHO. Ciência e tecnologia: para quê? Como?, p. 141.
}

dificuldades de criar uma empresa e, conseqüentemente, do natural receio de abandonar a segurança da universidade para enfrentá-las. A importância deste mecanismo torna imperativo que se criem formas de estimulálo, reduzindo o risco individual envolvido; por exemplo, licenças por até três anos. A universidade ganha em qualquer hipótese; se o pesquisador retornar, naturalmente manterá a interação. O governo pode estimular este mecanismo de várias formas: linhas especiais de financiamento para a criação de empresas, em particular para aquelas que se baseiem em resultados de pesquisas por ele financiados; apoio às universidades para a contratação de professores substitutos durante 0 período de licença e outros.

Um novo modelo de criação de empresas apareceu recentemente e deve receber todo o estímulo possível. Trata-se das 'Empresas Juniores', criadas por alunos, dentro da universidade, com a orientação de docentes. Obviamente, é um meio efetivo de formação de recursos humanos, além de obrigarem também os docentes a entender os problemas do meio empresarial"*.

Podemos afirmar que o processo de parceria universidade-empresa segue algumas fases que se iniciam no diálogo, intensificam-se com a convivência, até atingir a identificação cultural e a confiança.

Existem várias formas de se iniciar o diálogo, entre elas: a participação em congressos, exposições e feiras; visitas programadas às empresas; visitas de empresários a centros de pesquisa universitários; debates científicos sobre temáticas previamente definidas. A organização dessas atividades com entidades de classe pode ser fator de motivação para assistência de grande número de empresas. Na relação direta com os agentes produtivos, faz-se melhor o marketing do que com a propaganda institucional.

\footnotetext{
* RIPPER FILHO. Ciência e tecnologia: para quê? como?, p. 149-151.
}

Daí decorrem, normalmente, serviços especializados e consultorias e até parcerias de longo prazo. Às vezes, pequenos programas de assistência técnica, que cubram de forma parcial a necessidade dos usuários, dão origens a experiências de envergadura.

No contato com os empresários, é preciso interpretar suas necessidades e traduzi-las em demandas tecnológicas para universidades e instituições de pesquisa, que possuem em suas linhas de pesquisa com seus pesquisadores, a oferta tecnológica do processo.

Convém, ainda, uma observação: nem todas as empresas, principalmente as pequenas e médias, podem suportar o esforço necessário e o risco para manter uma posição de inovação sistemática.

Os empresários, particularmente os de pequenas e médias empresas dos países em vias de desenvolvimento, pensam, geralmente, em termos de problemas a resolver e projetam sobre essa base a demanda de colaboração externa.

O empresário não tem conhecimento se a solução do seu problema requer o desenvolvimento de uma nova tecnologia, a assimilação de uma tecnologia importada ou a utilização de uma tecnologia conhecida. Quando ele demanda a ajuda universitária é por não ter forma de resolver o problema internamente.

Embora algumas tarefas mais simples não devessem ser executadas por pesquisadores universitários, principalmente nos primeiros contatos com a empresa, a presença de professores e pesquisadores e sua participação direta em tarefas de colaboração, por mais simples que sejam, cria um clima de confiança e segurança e abre novas vias de colaboração para projetos de maior complexidade.

A vinculação universidade-empresa se apresenta em diferentes planos e requer ações específicas e complementares, entre elas podemos citar as seguintes: a formação dos quadros que a empresa requer para crescer e inovar, seja em nível de graduação, pós- 
graduação ou de atualização; acordos de transferência e colaboração incluindo serviços de pesquisa; a interação entre pesquisadores e profissionais de universidades e empresas como meio de facilitar a circulação de informação sobre tecnologias e suas fontes de obtenção.

A educação continuada tem sido uma linha de ação crescente nos países economicamente mais bem-sucedidos e tem se transformado em uma atividade importante das instituições de ensino superior, aportando às universidades recursos financeiros significativos. A educação continuada inclui cursos de especialização, extensão e atualização para profissionais de nível superior, programas de atualização e reciclagem de professores de primeiro e segundo graus e de escolas técnicas, programas de educação à distância para todos os graus de educação formal e de especialização profissional, treinamento técnico para trabalhadores, programas de formação técnica de profissionais ligados a organizações não-governamentais, formação de funcionários do governo e outros.

Como assinala Markovitch*, os membros do processo de inovação (universidades, indústrias, institutos de pesquisa e desenvolvimento e governo) devem buscar uma sinergia que lhes permita interação e busca de interesses comuns. Esse processo de interação é um desafio que surge como complementação ao desenvolvimento de cada um dos membros e, em conseqüência, da ciência, da tecnologia e da economia como um todo.

Assim, embora universidade e empresas possuam desafios tão distintos, comunidades internas tão diferentes, objetivos e expectativas tão distantes, como a inovação tecnológica é de interesse de ambas, podemos construir mecanismos que permitam cada qual desenvolver suas atividades, sem que haja uma descaracterização. É o que Angela Uller** chamou um processo de interação, e não de integração.

\footnotetext{
* MARCOVITCH. Administração em ciência e tecnologia.

** ULLER. Interação universidade e empresa, p. 9-10.
}

A parceria entre esses dois agentes sociais é possível desde que haja a predisposição à cooperação, o que exige flexibilidade e um redesenho permanente das instituições. A variável tecnológica e, em geral, o conhecimento constituem-se, na verdade, em um componente estrutural da estratégia das empresas. O valor dos produtos e serviços crescem como função dos conhecimentos neles incorporados, antes mesmo do valor das matérias-primas ou mão-de-obra que contêm.

É importante assinalar que a cooperação é um instrumento de interação e que a cooperação científica e tecnológica é uma das modalidades de cooperação que contribui de uma maneira decisiva, ainda que às vezes pouco visível, para a interação, por meio do conhecimento mútuo, do intercâmbio de experiência de atividades conjuntas, de alianças estratégicas, de coordenação de políticas, de difusão e transferência de conhecimentos e tecnologias.

A cooperação pode ser entendida, assim, como o elemento que torna possível a articulação e a integridade do sistema de inovação, até porque a tendência de crescimento dos custos de pesquisa e desenvolvimento tem provocado mudança na estratégia das empresas que tratam de dividir o risco da pesquisa pré-competitiva com o desenvolvimento de programas conjuntos com outras empresas e/ou universidades.

Assim, a pesquisa e desenvolvimento executados coletivamente por um conjunto de empresas é uma característica das novas formas de produção e da nova estruturação industrial.

Entre os elementos que afetam o processo de inovação, as oportunidades tecnológicas que se apresentam para as empresas e a capacidade das empresas para reconhecer e aproveitar estas oportunidades têm papel fundamental. Isto vai requerer, além de recursos humanos capacitados para trabalhar com as novas tecnologias, uma estrutura e organização da força de trabalho; uma estrutura financeira e uma estratégia de marketing.

\section{O PAPEL DOS AGENTES DE INTERAÇÃO}

Qualquer que seja o mecanismo de interação universidade-empresa a ser utilizado, há de se estar atento que as diferenças culturais são muito fortes e as formas de comunicação são distintas. O ideal é que haja um organismo de interface capaz de conhecer a linguagem empresarial, seu comportamento e expectativas e, ao mesmo tempo, conhecer a qualidade dos conhecimentos disponíveis, o potencial dos pesquisadores e sua equipe, e exercer papel de controle no cumprimento de prazos e tarefas.

Mediante o processo de interação, tanto universidade quanto empresa precisam estabelecer códigos comuns em busca do desenvolvimento tecnológico. Aí há de existir a tradução das linguagens do pesquisador e do empresário, que, por não estarem no mesmo ambiente, tratam do mesmo tema com enfoques e nomenclaturas diferentes. Uma das críticas mais generalizadas é a falta de conhecimento da dinâmica empresarial pela universidade, sobretudo quanto ao fator tempo.

Os profissionais que trabalham nessa interface podem ser chamados agentes de interação. $O$ agente de interação deve atuar dentro e fora da empresa buscando o que existe de novo no mercado e no meio científico. $\mathrm{Na}$ empresa, deve interagir com alguém que tenha conhecimento das atividades e operações da companhia, dos seus objetivos operacionais - com alguém com habilidades de interface e responsável pela manutenção da rede de contatos. Todavia, se não existir, ainda, na empresa, alguém com essas características, cabe ao agente de interação, por meio de relacionamento interpessoal, abrir caminho junto às empresas para potencializar a interação. É fundamental, portanto, que ele conheça bem a estrutura da instituição de pesquisa ou mantenha estreito contato com a interface da instituição de pesquisa para, a partir de relacionamento interpessoal e dentro de uma aproximação criativa e inovadora, estabelecer um fluxo de informações que contribua para o desenvolvimento de um produto ou serviço. 
De tudo, observa-se que o agente de interação deve possuir algumas características, entre elas: iniciativa, facilidade de comunicação, responsabilidade, capacidade de trabalhar em equipe, criatividade, espírito crítico, pontualidade, experiência em empresa, respeito acadêmico, visão empreendedora, postura adequada para ambos os ambientes, dinamismo, capacidade de manter sigilo e objetividade.

Cabe, ainda, destacar que, antes de qualquer contato com a empresa, é importante conhecer o setor e o ramo de atuação, bem como os dados da própria empresa. É importante, também, que o agente de interação esteja familiarizado com a rotina do pesquisador e do empresário e esteja atualizado quanto às tendências econômicas e sociais e o potencial tecnológico das instituições de pesquisa.

Os agentes de interação, que no nosso contexto podem ser chamados de agentes de inovação tecnológica, devem conhecer os diversos obstáculos que existem na cooperação universidade-empresa, assim como as várias motivações observadas tanto do lado da universidade quanto do lado da empresa, e tentar trabalhá-las.

Comecemos pelos obstáculos: diferentes objetivos e missões; diferentes atitudes para a colaboração; diferentes estilos de gestão; diferentes noções de confidencialidade; diferentes enfoques dos direitos de propriedade industrial ou intelectual; diferentes motivações para colaborar.

Entre as motivações para colaborar, do lado das universidades, encontramse acesso à fonte alternativa e flexível de recursos que Ihes aliviem a escassez orçamentária e lhes permitam atualizar material bibliográfico, acesso a equipamentos de pesquisa mais modernos, impulso à formação de pesquisadores, conhecimento dos problemas reais da empresa, em nível da pesquisa, e possibilidade de aumentar a renda dos pesquisadores universitários.
Já as empresas, que centram seus esforços em conseguir maior crescimento com a comercialização de produtos e processos, têm as seguintes motivações: acesso a pessoal de pesquisa altamente qualificado; acesso a soluções de problemas técnicos específicos; apoio e impulso à excelência técnica; aumento do prestígio e da imagem; acesso a recursos públicos; necessidade de reduzir custos sem aumentar o pessoal próprio de P\&D nem proceder a importantes modificações administrativas; necessidade de renovar o acervo de conhecimentos por meio de uma atividade de P\&D continuada; crença no valor estratégico da inovação tecnológica a curto e longo prazo.

Assim, é necessário conseguir um clima social e político adequado e promover uma cultura pró-empresarial nas universidades.

Por outro lado, é preciso preparar as empresas para identificar e aproveitar oportunidades tecnológicas, o que só se viabiliza se os agentes de interação conhecerem bem 0 ambiente das empresas.

Nos países subdesenvolvidos, existem algumas dificuldades das empresas no aproveitamento dessas oportunidades. Entre outras, como assinala Alvarez*, podemos citar as seguintes: organização incongruente; pouca valorização e utilização de resultados científicos e tecnológicos; utilização imprópria dos recursos humanos existentes; falta de preparação e emprego de técnicas gerenciais e financeiras modernas; inadequada hierarquização do tempo.

Convém comentar, também, sobre as inter-relações tecnoeconômicas estabelecidas pela indústria e seus reflexos no processo de geração e difusão de inovações. Para tanto, utilizamos a classificação de Pavitt, citada por Meirelles ${ }^{\star *}$ :

\footnotetext{
* ALVAREZ. Ciencia y tecnologia, p. 28.

** MEIRELLES. Tecnologia, transformação industrial e comércio internacional, p. 114.
}

1) Indústrias "dominadas pelos fornecedores" (supplier-dominated) As inovações são fundamentalmente de processo, geradas por firmas externas à indústria e incorporadas aos equipamentos e aos insumos intermediários. Nestas indústrias o processo de inovação é um processo de difusão de novas "safras" de bens de capital e de insumos. Indústrias deste tipo são, por exemplo, a indústria têxtil, a de papel e a de madeira.

\section{2) Indústrias "intensivas em esca-} la" (scale-intensive) - As inovações são de produto e de processo. O processo de produção é complexo, com significativas economias de escala. As firmas tendem a ser grandes e integradas verticalmente, produzindo boa parte de suas inovações de processo e destinando volumes importantes de recursos a atividades de P\&D. Exemplo de indústrias deste tipo são as indústrias de manufaturas de metal, alimentos, cimento e bens elétricos duráveis.

3) Indústrias de "fornecedores especializados" (specialized-suppliers) - As inovações são principalmente de produto, utilizadas em outras indústrias como bens de capital. As firmas são pequenas e especializadas e atuam em estreita interação com o usuário. As indústrias de instrumentos de engenharia e de mecânica são exemplo deste tipo de indústria.

4) Indústrias "baseadas na ciência" (science-based) - O processo de inovação está diretamente ligado à oportunidade tecnológica aberta pela aparição de um novo paradigma. As firmas tendem a ser grandes (com a exceção das pequenas firmas "schumpeterianas" altamente especializadas) e intensivas em P\&D. Estas indústrias oferecem bens de capital e bens intermediários a um conjunto amplo de indústrias. É o caso da indústria eletrônica e de boa parte da indústria química.

Como visto, tal classificação permite visualizar, pelo grau de inserção da indústria na matriz de relações interindustriais, as especificidades da geração e utilização de inovações tecnológicas. 
De igual modo, entendendo grupos estratégicos como aqueles constituídos por firmas cujas estratégias competitivas estão mais próximas entre si e como tal seguem comportamentos similares, convém enumerar os seis tipos de estratégias relativas a inovação tecnológica, segundo Freeman*:

a) Estratégia ofensiva - consiste em obter a liderança técnica e de mercado, indo na frente na introdução de novos produtos. As firmas que seguem uma estratégia ofensiva são intensivas em P\&D e, particularmente, dispõem de uma elevada capacidade em engenharia de projeto e em atividades de pesquisa aplicada. Um certo esforço de pesquisa básica na firma e um contato estreito com os centros de pesquisa básica também parecem ter uma contribuição significativa para o sucesso da estratégia ofensiva.

b) Estratégia defensiva - Estas firmas são também intensivas em $P \& D$, mas diferenciam-se das primeiras na natureza e no timing das inovações. Elas não são capazes de desenvolver inovações originais, mas são capazes de responder rapidamente às inovações introduzidas pelo líder, de modo a poder conservar sua participação no mercado. Estas firmas aproveitam os novos mercados abertos pelo inovador e aprendem com os erros que este comete, de forma que, freqüentemente, obtêm benefícios superiores aos do próprio inovador. As firmas que seguem uma estratégia defensiva devem ter uma elevada capacidade em desenvolvimento e projeto experimental.

c) Estratégia imitativa - As firmas imitativas devem dispor de certas vantagens para poder competir com o inovador, como o acesso a mercados cativos, custos menores ou proteção política. Além disso, devem ter elevadas capacidades em engenharia de produção e projeto e devem ser capazes de operar com alta eficiência o processo de produção (a não ser que estejam protegidas por elevadas tarifas alfandegárias). Estas firmas podem disputar agressivamente o mercado quando a tecnologia da indústria tende a estabilizar-se.

\footnotetext{
* FREEMAN. The economics of industrial innovation, p. 216
}

d) Estratégia dependente-As firmas que seguem esta estratégia desempenham um papel subordinado na indústria. Elas não realizam atividades de P\&D e dependem das especificações técnicas de seus clientes (geralmente grandes firmas). As firmas dependentes, além do mais, freqüentemente são utilizadas como um colchão amortecedor das flutuações do mercado.

e) Estratégia tradicional - Esta estratégia é seguida por aquelas firmas que atuam em indústrias onde tem diminuído o dinamismo tecnológico. Não realizam atividades de $P \& D$, atuam em mercados altamente atomísticos ou em oligopólios fragmentados.

f) Estratégia oportunista - Este tipo de estratégia é seguido naquelas situações em que a firma pode ocupar um nicho ou oportunidade de mercado a partir do senso ou capacidade empresarial, sem incorrer em gastos de P\&D.

Na verdade, são os agentes de inovação tecnológica ou os agentes de interação os responsáveis pelas várias formas de transferência de tecnologia. Para tanto, é importante que estejam também atentos aos diversos modelos de desenvolvimento tecnológico existentes, a saber:

1) Modelo de inovação empresarial diversificado - Os parques tecnológicos que se constituem em regiões onde estão disponíveis ou se pode gerar condições favoráveis ao desenvolvimento de atividades de alta dinâmica inovadora, entre elas recursos naturais valiosos, infra-estrutura técnico-científica, universidades ou faculdades de excelência em algumas especialidades, entre outras. O principal objetivo de um parque tecnológico é criar os meios e mecanismos para que se estabeleça o nexo mais estreito possível entre as universidades, os centros de P\&D e o setor produtivo.

2) Modelo de inovação empresarial centralizado - Constituído pelas companhias multinacionais que geram e impõem padrões tecnológicos universais a partir da contratação de centros de pesquisa e empresas de alta inovação tecnológica.
3) Modelo de desenvolvimento tecnológico baseado em políticas estatais e mercado nacional fechado - O modelo japonês, em que há uma conexão entre o Estado e as grandes empresas, com base no planejamento estratégico, baseado em objetivos nacionais. Nele, verifica-se a combinação entre tecnologia e gestão estratégica empresarial com dinamismo empresarial.

4) Modelo de desenvolvimento tecnológico baseado em políticas estatais e mercado nacional aberto O modelo francês, com forte planejamento estratégico governamental e subvenção a empresas nacionais importantes, objetivando o aumento da competitividade tecnológica interna e no mercado internacional.

5) Modelo de substituição de importação - O modelo da América Latina. A transferência de tecnologia se dá mediante cópia de produtos de tecnologia avançada e com a formação e a participação de técnicos e especialistas nacionais no estrangeiro.

6) Modelo de superioridade tecnológica militar - Adotada por quase todos os países desenvolvidos, exceção do Japão e Alemanha, destacando-se, principalmente os Estados Unidos e a extinta União Soviética. Nos Estados Unidos, apesar de parte dos recursos básicos terem tido como fonte a Secretaria de Defesa do Governo, a execução das tarefas de P\&D e sua implementação estiveram a cargo de centros de pesquisas, universidades e empresas que se dedicavam a atividade civil e comercial, resultando, juntamente com o cumprimento dos objetivos bélicos, em novas modalidades e novas aplicações desse desenvolvimento, com fins puramente econômicos.

7) Modelo de cooperação intergovernamental e empresarial no âmbito internacional - Partindo do pressuposto de que na atualidade é impossível, para uma nação média ou pequena, obter níveis de excelência e competitividade internacional na maioria dos setores e atividades avançadas, estão sendo estabelecidos programas regionais de cooperação científica, tecnológica e produtiva envol- 
vendo instituições, centros de pesquisa, universidades, empresas e governos de diferentes países. O exemplo mais conhecido é o programa Eureka da Comunidade Européia.

8) Modelo de adaptação e difusão de novas tecnologias no âmbito de indústrias tradicionais - Os exemplos mais típicos são da Alemanha e Itália, onde se estabelece um mecanismo de cooperação entre empresas e governos, com vistas, não a gerar novas tecnologias nem novos campos de conhecimento científico, e, sim, a experimentar e introduzir novos produtos e processos que permitam renovar indústrias tradicionais. Esse modelo resulta atrativo para nações com um grau de desenvolvimento emergente, as quais, sem abandonar possíveis avanços na direção de tecnologias de ponta, combinam esse propósito com o da indústria tradicional.

\section{University-enterprise interaction in the knowledge society: reflections and reality}

\section{Abstract}

The purpose of this paper is to arouse a deeper reflection on university-enterprise as a vital element in knowledge society. The main reasons for this interaction process in face of the technological paradigm are presented in the introduction and point out to the main problems of science and technology in Latin America, with particular emphasis on the Brazilian economy, having as its backdrop the setting-up of an innovation system.

In Section 2, the main existing advantages and disadvantages mechanisms of interaction are analyzed. The role of the interaction agents in that interface work is dealt with in Section 3.

A suitable profile of the agents and the knowledge they should have are described, both the university environment and the entrepreneurial sector, to no detriment, of course, of the different models of technological development. As a conclusion, a reflection about the role of Brazilian State is presented as a leading actor for the technological development, including support to interface institutions.

\section{Keywords}

Knowledge society; Technological innovation; University-enterprise interaction.
Todos esses aspectos devem ser do conhecimento pleno do agente de interação, que - esperamos comece a ficar claro - tem um papel fundamental como implementador de elementos facilitadores dos instrumentos de interação necessários à competitividade das empresas, principalmente na sociedade do conhecimento.

Antes, porém, gostaríamos de uma reflexão adicional: visualizada a importância dos agentes de interação, que se acentua na sociedade do conhecimento, não seria função também do governo a manutenção de instituições que absorvessem tais profissionais, principalmente em se tratando de economias periféricas? Países como a Inglaterra vêm mantendo, com expressiva quantia de recursos governamentais, instituições com essas características. Não é chegada a hora de o Estado brasileiro repensar o seu papel como indutor do desenvolvimento tecnológico e da importância dos agentes de interação universidadeempresa?

\section{REFERÊNCIAS BIBLIOGRÁFICAS}

1. ALVAREZ, B. Ciencia y tecnologia: retos del ordem mundial para la capacidad de investigación en America Latina. Colombia: Benjamim Alvarez/Hernando Gómez, 1993. p. 28.

2. COUTINHO, Luciano G. Superação da fragilidade tecnológica e a ausência de cooperação. In: MUSA, Edson Vaz et al. Ciência e tecnologia: alicerces do desenvolvimento. São Paulo: Cobram, 1994. 164 p. p. 119

3. DIAS, Adriano Batista. Alta tecnologia: reflexos, reflexões. Recife: Fundação Joaquim Nabuco, 1996, p. 120-121.

4. DUTRENIT, G. "Sistema Nacional de Innovación" (mimeo).

5. FONT, Mario Fernández. Innovación tecnológica y competitividad: un intento de divulgación de conceptos, enfoques y métodos. Cidade do México: FESCARIBE, 1997. 223p. p. 99.

6. FREEMAN, C. The economics of industrial innovation, Peguin, Hardmondsworth, 1974. p. 216.

7. MARCOVITCH, Jacques. Administração em ciência e tecnologia. São Paulo: Edgard Blucher, 1983.
8. MEIRELLES, José Gabriel P. Tecnologia transformação industrial e comércio internacional: uma revisão das contribuições neoschumpeterianas, com particular referência às economia da América Latina. Campinas: Universidade Estadual, 1989. 222 p. p. 114 (Dissertação de mestrado apresentada ao Instituto de Economia da Universidade Estadual de Campinas).

9. MOTA, Teresa Lenice N. da Gama. Sistemas de inovação tecnológica de economias periféricas. Fortaleza, 1998. 66p. (Monografia apresentada à Universidade Estadual do Ceará UECE, como exigência parcial para obtenção do título de Especialista em "Agente de Inovação Tecnológica").

10. PORTER, Michael. "The Competitive Advantage of Nations". Harvard Business Review, marzo-abril 1990, p. 73-93

11. RIPPER FILHO, José Ellis. Ciência e tecnologia: para quê? como? In: MUSA, Edson Vaz et al. Ciência e tecnologia: alicerces do desenvolvimento. São Paulo: Cobram, 1994. 164 p. p. 141.

12. ULLER, Angela. Interação universidade e empresa: mitos e fatos. Informe PADCT, Brasília, v. 5, n. 21, p. 9-10, out. 1995.

\section{Teresa Lenice Nogueira da Gama Mota}

Professora Visitante da Universidade Estadual do Ceará. Superintendente do Instituto Euvaldo Lodi - Núcleo do Ceará. 